\title{
Social Aspects of Antibiotic use in the South and East Asian Students and General Population
}

\author{
Jas Min Oh', Long Chiau Ming ${ }^{2,3}$, Faizah Safina Bakrin³, Bey Hing Goh ${ }^{1}$, Learn Han Lee', Tahir Mehmood Khan ${ }^{1 *}$ \\ 'School of Pharmacy, Monash University Malaysia, Sunway City, Selangor, MALAYSIA. \\ ${ }^{2}$ Pharmacy, School of Medicine, University of Tasmania, AUSTRALIA. \\ ${ }^{3}$ School of Pharmacy, KPJ Healthcare University College, Nilai, Negeri Sembilan, MALAYSIA.
}

\begin{abstract}
Background: This study explored the knowledge of attitudes to and perception of consumption of antibiotics, and understanding of antibiotic resistance among students and general population across South and East Asia region. Method: A systematic review was performed through PubMed, Scopus, EBSCOhost (Medline) and EMBASE scientific databases. Cross-sectional studies aimed to investigate the knowledge of, attitude to and perception of antibiotic use as well as studies concerning the demand of antibiotics, antibiotic resistance were evaluated. Other inclusion criteria were: studies published in English prior to July 2016; survey that examined one of the 7 topics proposed by Gualano et al. (2015) in their systematic review on knowledge and attitudes about antibiotics. Results: A total of 9 studies were selected for systematic review. A lack of knowledge about antibiotics was identified. Approximately $50 \%$ of the sample mistakenly believed that antibiotics could treat viral infections which are commonly responsible for the common cold, sore throat and cough. The majority (above $60 \%$ ) of the sample were compliant with completing a full course of antibiotics but unfortunately $40 \%$ of the sample still self-
\end{abstract}

administered antibiotics without prescription. Conclusion: Knowledge of, attitudes to and perceptions of antibiotic use are found to be inappropriate among the student and general public in the South and East Asia region. Although antibiotic resistance is a global issue, every country in the South and East Asia region is encouraged to take their own initiative to curb antibiotic resistance.

Key words: Antimicrobial resistance; Prescribing practice; Anti-infective agents; Antibacterials; Pharmacoepidemiology.

Correspondence

Dr. Tahir Mehmood Khan, School of Pharmacy, Monash University, Jalan Lagoon Selatan, 47500 Bandar Sunway, Selangor, Darul Ehsan, MALAYSIA.

Phone: +(603) 55144418

Email: tahir.mehmood@monash.edu

DOI: 10.5530/jyp.2018.10.16

\section{INTRODUCTION}

Antimicrobial resistance (AMR) has gathered attention by the health authorities in South and East Asian region (SEAR) due to the awareness on the emergency of multiple drug resistance microorganism. It is a worrying trend that student and general public seek antibiotics common conditions include cough with sputum, common cold, fever or symptoms related to upper respiratory tract infections which are commonly of viral origin. ${ }^{1}$ Previous studies have shown that demographic characteristics influence antibiotic use and knowledge. ${ }^{2}$ People with lower levels of education, elderly and those with no exposure to education campaigns are more likely to have poorer knowledge of antibiotic resistance and the role of antibiotics and a poorer attitude towards antibiotic usage. ${ }^{2}$

According to an American study, higher misconceptions of antibiotic use is caused by lower socioeconomic status and lower educational status, and changes according to demographic characteristics. ${ }^{3}$ In certain developing countries in Asia, antibiotics can be readily purchased without prescription from pharmacies, and drug stores. ${ }^{4}$ Buying antibiotics without prescription or demanding antibiotic from doctors are common. In Nepal for example, there are four times more retail drug store than government hospitals and healthcare centers. Common cultural beliefs from developing countries include that antibiotics can effectively treat most illnesses and that different conditions call for different type of antibiotics. ${ }^{5}$ To date there has been no systematic review done in SEAR to understand the status of resistance, trends and consumption of antimicrobial agents. ${ }^{6}$ In order to tackle the growing problem of antibiotic misuse, an in-depth insight into the public perception and knowledge in this regard is crucial. A thorough understanding of public perception would allow policy maker to design a targeted awareness campaign to increase their knowledge. Thus, our aim for this study was to identify knowledge of the role of antibiotics, attitudes to and perception of consumption of antibiotics, and understanding of antibiotic resistance among students and general population across SEAR.

\section{METHOD}

\section{Search strategy and screening process}

Scientific literature from four databases were searched from their inception up to 31 st July 2016 relating to the student and general public's knowledge of, attitude to and perception of antibiotic use in World Health Organization's (WHO) SEAR. Databases used include PubMed, Scopus, EMBASE and EBSCOhost. All articles limited to search terms in titles, abstracts and journal articles were included. This included all papers not written in English provided that an English abstract with sufficient information was provided. After removal of duplicated articles, titles and abstracts were screened by the first author. Then, all researchers read the full text articles to screen for inclusion eligibility. All authors discussed any discrepancies until mutual agreement was achieved.

\section{Inclusion Criteria \\ Types of studies}

Primary quantitative studies using structured questionnaire cross sectional study design. 


\section{Countries}

Using WHO classification of SEAR: Indonesia, Sri Lanka, Thailand, Timor-Leste, Bangladesh, Bhutan, Republic of Korea, India, Maldives, Myanmar, Nepal.

\section{Participants}

Studies of student and general public were included. Studies that only defined the participant group as 'primary/secondary/intermediate school' were excluded because this generally included adolescent below 18 years old.

\section{Scope/aim of the studies}

This review was limited to study addressing nine essential topics as applied by Gualano et al. on their published systematic review and metaanalysis on knowledge and attitudes about antibiotics: ${ }^{7}$

1. Have you self-administered antibiotics in the last 6 months?

2. Presence of antibiotics at home and source.

3. Can antibiotics treat bacterial infections?

4. Can antibiotics treat viral infections?

5. Are you aware that coughs and colds are caused by virus?

6. Are antibiotics useful for cold and flu and can they shorten the duration of the illness?

7. Are you aware of antibiotic resistance?

8. Do you stop taking antibiotics when you feel better?

9. How often do you take antibiotics?

\section{RESULTS}

Based on the 9 articles included (Figure 1), there are papers regarding student and general public in India $(n=4)$, Korea $(n=2)$, Thailand $(n=1)$, Sri Lanka $(n=1)$ and Indonesia $(n=1)$. All studies included were done using a cross-sectional based survey, some being prospective $(n=5)$ and the others retrospective $(n=4)$. The retrospective studies were within three to six months of illness recall. Most were done using self-administered questionnaires $(n=6)$ while some involved phone or face-to-face interviews using a validated questionnaire $(n=3)$. Demographic characteristics are as mentioned in Table 1. The studies included studies consist of a range of 97 to 1177 respondents, above 18 years old and mostly female. Detailed data extraction is shown in Table 2.

\section{Attitudes and perception towards antibiotic resistance}

Focusing on India, a survey conducted at the Hospital for Children in Vashi, Navi Mumbai reported that amongst parents, only $15.5 \%(\mathrm{n}=135)$ knew about antibiotic resistance, and more than a quarter (26.4\%, $\mathrm{n}=230$ ) believed that excessive antibiotics usage would not have any detrimental effects. ${ }^{8}$ Moving on to health undergraduates, it is worth mentioning that in a study among Bachelor of Pharmacy (BPharm) and Doctor of Pharmacy (PharmD) students, few were aware of the superbugs concept $(2.3 \%$ vs $28 \%, n=2$ vs $n=14)$. It is also worrying that only $19.5 \%(n=17)$ of BPharm students believed that empirical therapy could promote resistance compared to $48 \%(n=24)$ of their PharmD counterparts. ${ }^{9}$ On the other hand, in a study among dental undergraduates, $64 \%(n=49)$ agreed that self-medication with antibiotics could promote resistance. ${ }^{10}$ A study performed at a teaching dental hospital in North India, the results showed $68.4 \%$ of the responded dental undergraduates and $85.1 \%$ interns buy antibiotics directly from local pharmacies without proper prescription based on previous experience with the same symptoms. ${ }^{10}$ Another survey conducted amongst medical students reported that $90.7 \%(n=88)$ agreed that excessive and unjustified use of antibiotics would lead to a global health security threat. However, this figure de- creases when the participants were asked if AMR is a prominent health care threat in their hospital $(68 \%, \mathrm{n}=66)$, or country $(88.65 \%, \mathrm{n}=86){ }^{3}$

In a Korean study, $65 \%(n=760)$ of the public participating in the survey had precise antibiotic resistance knowledge. However, only $33 \%(n=33)$ knew that antibiotic resistance can spread between bacteria. ${ }^{2}$ With regards to the parenting community in Korea, $77.4 \% \quad(n=393)$ agreed that antibiotic resistance is problematic. Moreover, they were also convinced that irrational prescribing and uptake of antibiotics in primary care is a contributing factor to antibiotic resistance $(77.6 \%, \mathrm{n}=394) .{ }^{6}$ The study also reported $73 \%$ of physicians stated that they feel the need to prescribe antibiotics because parents expect them. However, only $2 \%$ of parents reported demanding for antibiotics. ${ }^{6}$

In a survey of Thai students, $66 \%(n=470)$ respondents reportedly had correct knowledge that uncontrolled and irrational use of antibiotics could lead to drug resistance. ${ }^{1}$ However, according to a survey in Indonesia, $51 \%(\mathrm{n}=283)$ of the public were familiar with antibiotics, $85 \%(n=240)$ of whom knew that an improper and injudicious use of antibiotics would lead to antibiotic resistance in the near future. Unfortunately, there were also $24 \%(n=134)$ who reckon that antibiotics will not cause any adverse effect. ${ }^{4}$ A study in Sri Lanka reported that 59.8\% $(n=147)$ of undergraduates had poor knowledge of antibiotic side effects and were unaware of the issue of antibiotic resistance. ${ }^{5}$

\section{Knowledge on use of antibiotics}

A study in Korea showed that most respondents $(76.5 \%, \mathrm{n}=900)$ knew that virus causes common colds and coughs. Nevertheless, the majority of them $(70 \%, \mathrm{n}=824)$ were not aware that common colds and cough will not be cured by antibiotics. More than half $(57.2 \%, n=673)$ were unaware that some side effects of antibiotics include killing normal gut flora and flora. ${ }^{11}$ In a separate study in Korea, more than $70 \%(n=449)$ of the physicians and pharmacists knew the etiology of common colds but majority of the respondents $60.2 \%(n=709)$ of parents who believed the duration of the common cold in children whereas $34.1 \%(n=401)$ think that the complications of colds are reduced by antibiotics. ${ }^{12}$

In India, a study between BPharm and PharmD students discovered that there was a considerable knowledge gap. There were significantly more PharmD students $(64 \%, \mathrm{n}=32)$ than B Pharm students $(24.1 \%, \mathrm{n}=21)$ that correctly identified indication of antibiotic use. ${ }^{13}$ In a separate survey among medical students, $77.3 \%(n=75)$ knew that colds and flu were not caused by bacteria although the remainder $(22.7 \%, n=22)$ were totally ignorant about this. ${ }^{14}$ Similar to dental undergraduates, there are still some second year students and interns who agree that viral infection should be treated with antibiotics $(40.7 \%$ vs $24.3 \%, \mathrm{n}=31$ vs 18$)$. This study also mentioned that only $20.5 \%(\mathrm{n}=8)$ of second year students and $23.6 \%(n=130)$ of interns had a good knowledge of antibiotics. ${ }^{15}$ In the parenting community in India, most of the respondents were confused regarding the indication of antibiotic use. 400 parents (45.9\%) answered that antibiotics can be used for any microorganism while only 244 parents (28\%) knew that antibiotics are used against bacterial infection. ${ }^{16}$ According to a study on the Indonesian population, most participants $(74 \%, n=474)$ believed that antibiotics might exert health protective or even prophylaxis effect. ${ }^{17}$ This misconception stretches to a survey on Sri Lankan undergraduates that mentioned that the common cold and fever can be treated with antibiotics. ${ }^{18}$

With regards to Thai high school students, the majority of them correctly identified that antibiotics are helpful for bacterial pharyngitis $(71.9 \%$, $\mathrm{n}=512)$. Many could also reason that colds are caused by viruses $(88.2 \%)$ and that they would cure by themselves $(70.2 \%, \mathrm{n}=351)$. 


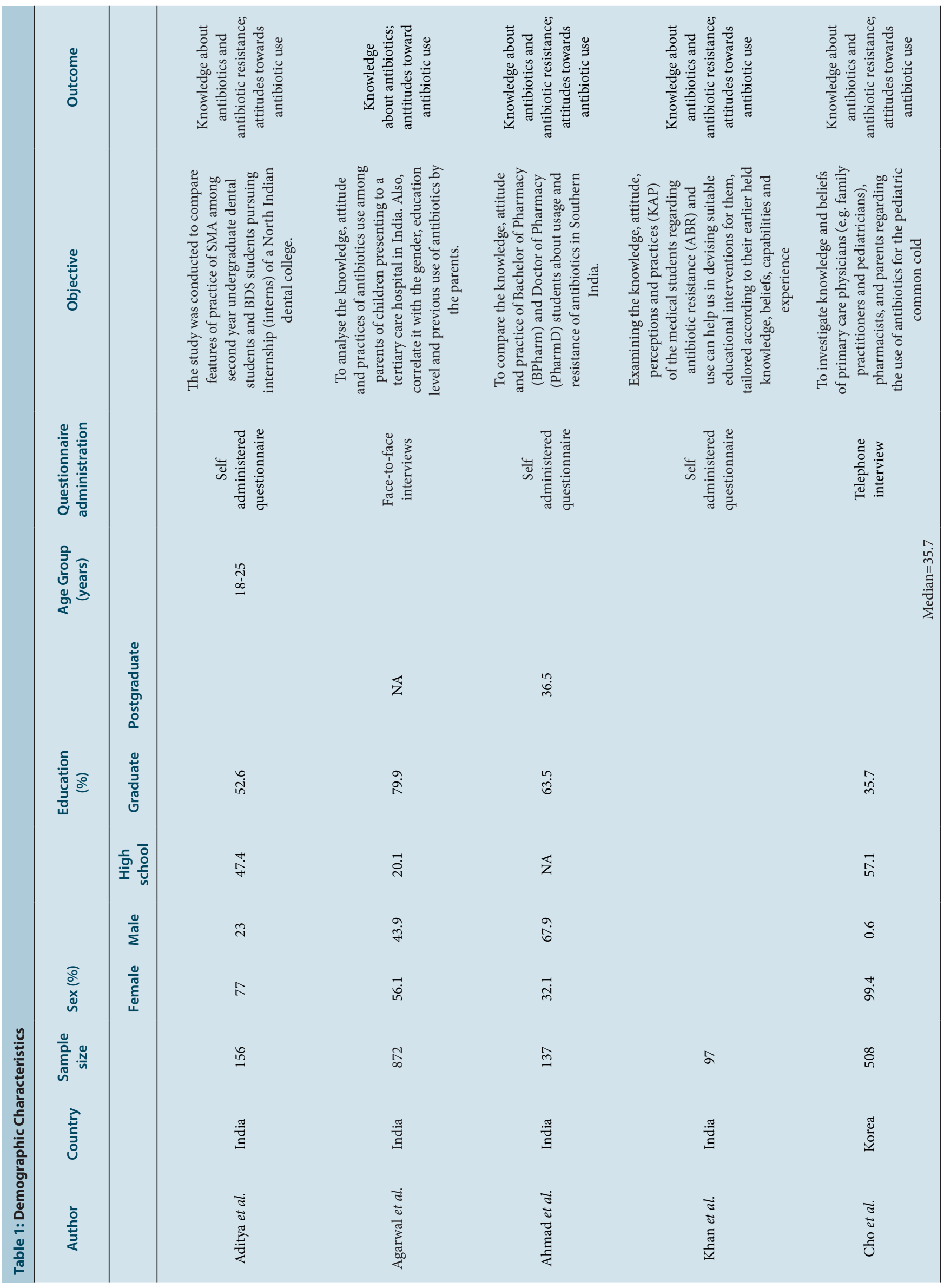




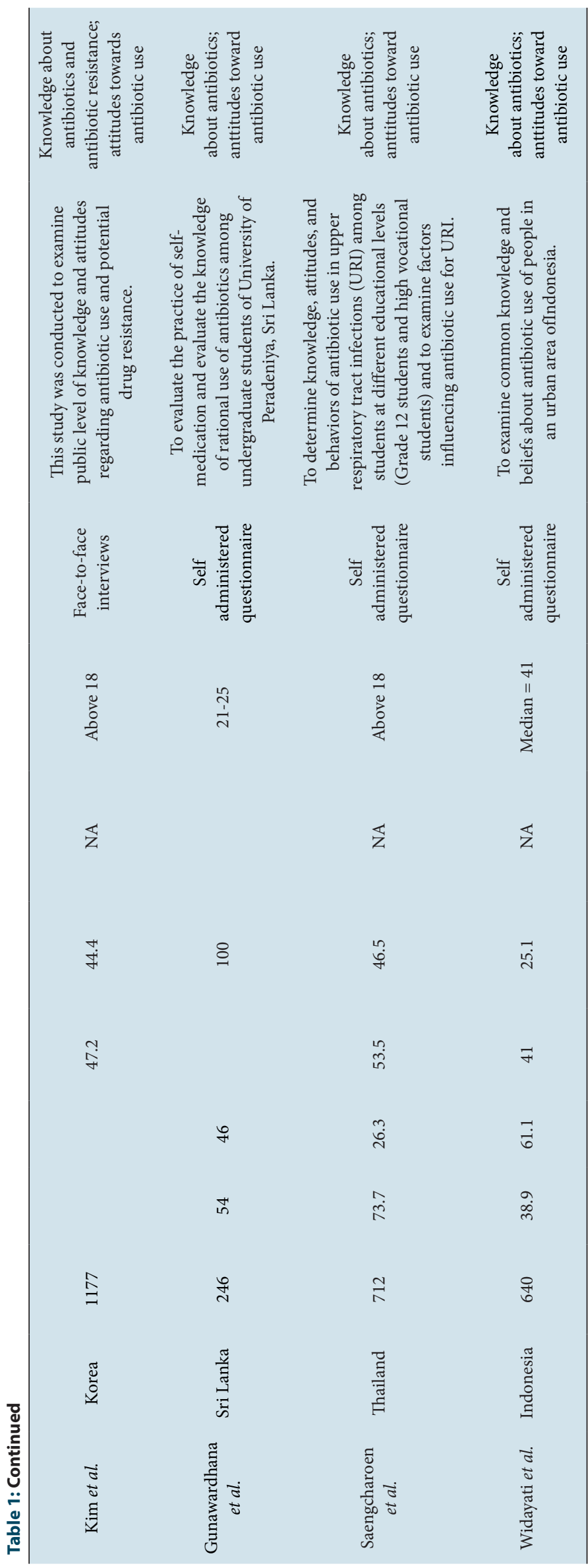

\section{Attitudes toward antibiotic use}

Results show that self-medication with antibiotics is more prevalent amongst students and adults than parents. For instance, $74.3 \%$ of dental interns reported self-medication with antibiotics in the past six months. ${ }^{10}$ In India, a survey on parents reported that $85.2 \%(n=743)$ would not use leftover antibiotics from previous prescription for their child. These parents were also highly compliant because $83 \%(n=724)$ responded that their child completed the course of antibiotics as prescribed by the doctor. ${ }^{16}$ For medical students in India, most of the undergraduates $(74.2 \%, \mathrm{n}=72)$ often tend to complete the full course of prescribed treatment. A significant majority $(92.8 \%, \mathrm{n}=90)$ habitually consulted a doctor before starting an antibiotic course. ${ }^{14}$ However, a study of pharmacy students revealed that only $55(63.6 \%)$ of BPharm students consulted a physician before taking antibiotics. ${ }^{13}$ Adoption of self-medication behavior was attributed to easy availability of antibiotics as well as reflection of previous successful antibiotic regiment. Based on a study among dental undergraduates, $41 \%$ of both second year students $(n=16)$ and interns $(n=23)$ reported self-medication with antibiotics due to similar past experience. They also added that they mainly obtain antibiotics from pharmacy stores ( $68.4 \%$ vs $85.1 \%, \mathrm{n}=51$ vs 65$)$, followed by home medicine cabinets $(28.9 \%$ vs $12.1 \%, \mathrm{n}=21$ vs 9$) .{ }^{15}$

Similarly, in a public study in Korea, $46.9 \%(n=542)$ respondents had unconsumed antibiotics obtained from previous prescriptions and $77.6 \%(\mathrm{n}=891)$ admitted that they stopped an antibiotic course when they felt better. The main reason respondents practiced self-medication with antibiotics was because they believed that antibiotics boosted their immunity prompting faster recovery from colds $(48.2 \%, \mathrm{n}=561) .{ }^{11}$ In a parenting community in Korea, only $2.2 \%(n=11)$ parents urged for a prescription for antibiotics. In addition, more than a quarter $(31.5 \%$, $\mathrm{n}=160$ ) thought that doctors prescribe too many antibiotics and $23.8 \%$ $(n=121)$ agree that some doctors prescribe antibiotics unnecessarily for financial benefit. ${ }^{12}$

From a survey of Thai students, it was found that only $10.1 \%(n=23)$ of grade 12 students in large cities, $4.6 \%(n=6)$ grade 12 students in small cities and $6.3 \%(n=21)$ high vocational students stated that antibiotics should be taken for 10 days or more. Most incorrectly believed that antibiotics should be taken for less than 4 days ( $34.7 \%$ vs $52.7 \%$ vs $60.2 \%$, $\mathrm{n}=79$ vs 81 vs 199). ${ }^{19}$ Conversely, in a study on Sri Lankan undergraduates, a higher proportion of students $(46.3 \%, \mathrm{n}=114)$ agreed that an antibiotic course should be taken for 3-4 days or 10 days while $18.3 \%(n=45)$ incorrectly believed that antibiotics should be taken for less than 3 days. ${ }^{18}$

\section{DISCUSSION}

This systematic review aimed to compile different studies published about SEAR that assessed the student and general public's knowledge of the role of antibiotics, attitude and perception towards consumption of antibiotics and understanding of antibiotic resistance. According to the WHO, there is currently no systematic up-to-date review that focuses on SEAR. ${ }^{20}$ The analysis conducted on the nine studies included revealed interesting results. Approximately $50 \%$ of the sample mistakenly believed that antibiotics could treat viral infections which are commonly responsible for the common cold, sore throats and coughs. Although the majority (above 60\%) are compliant in completing a full course of antibiotics, there are still approximately $40 \%$ of the sample that self-administered antibiotics without prescription. Also, around 35\% of the sample were unaware that misuse of antibiotics could contribute to antibiotic resistance, though $70 \%$ of the respondents agreed that taking antibiotics too often results in harm. So the findings of this review highlighted the main contributor in the misuse of antibiotics in SEAR is the lack of antibiotic knowledge among SEAR's student and general public. 


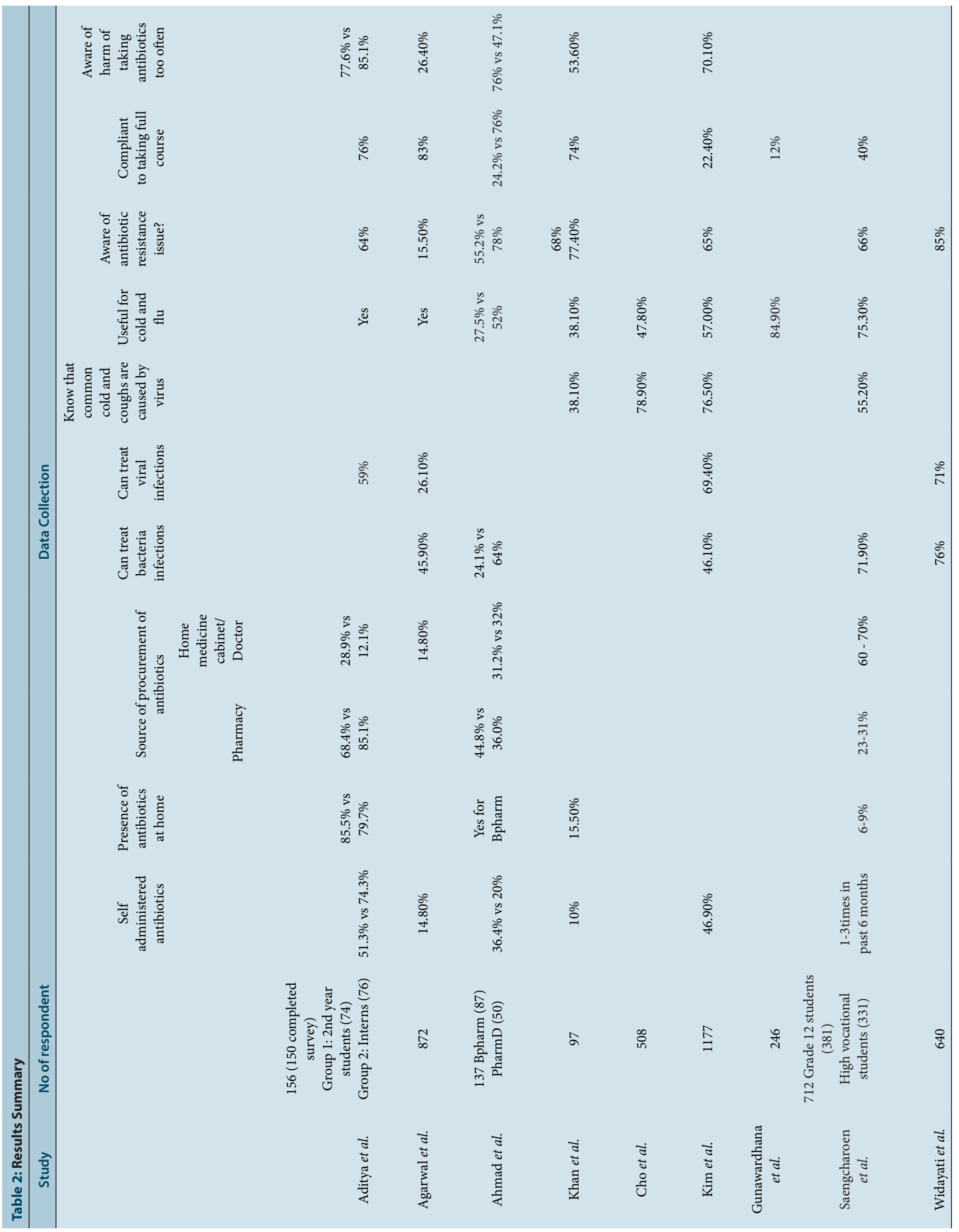




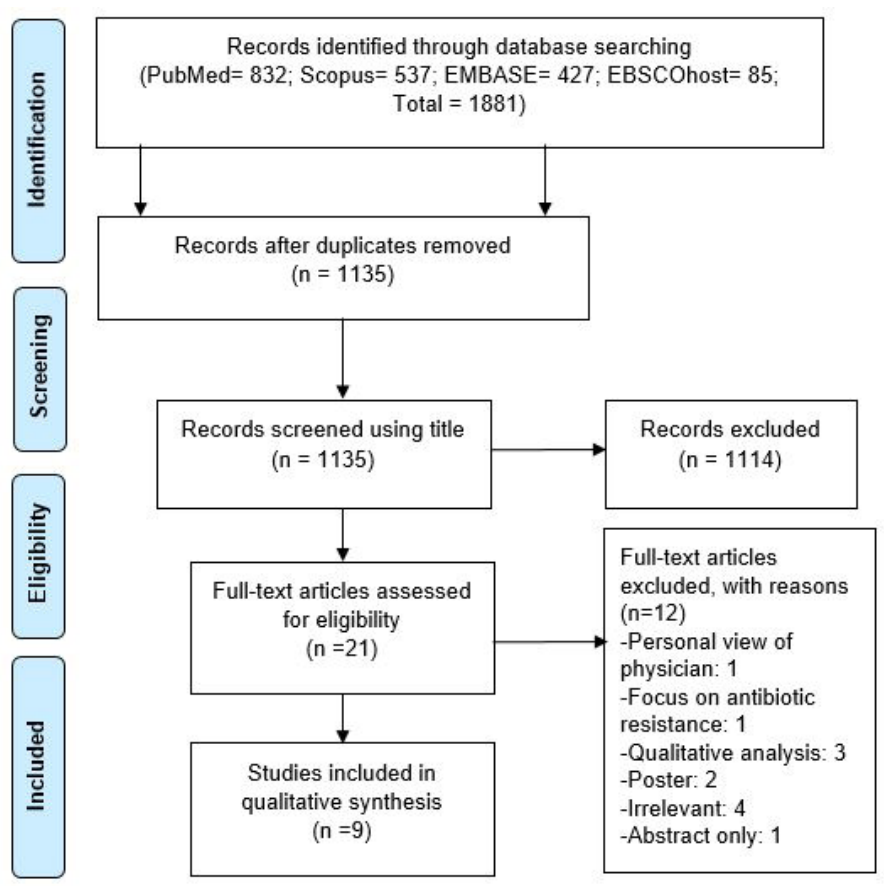

Figure 1: PRISMA Flow diagram.

Findings show that socio-demographics play an important role in antibiotics knowledge. A higher educational level is associated with better knowledge of and attitudes about antibiotics in general. ${ }^{3,21,22}$ This correlation is likely to be held by the population that consists of more males, younger people, and for those with a higher income level. ${ }^{18}$ In the case of Thai students, Grade 12 students in the city have higher knowledge score than those in the rural areas because they recently learned about antibiotic use in health education courses. ${ }^{19}$ This pattern is similar to a study of Sri Lankan undergraduates. Students of lower income families have lower mean score of knowledge compared to those of moderate or high income (above Indian Rupees 36500). Families of lower income are associated with lower education level. ${ }^{18}$

Another study in the United States (US) presented a similar reflection in this regard. The study reported that $80 \%$ of non-Hispanic whites strongly agree about the prevalence of antibiotic resistance as compared to $49 \%$ of Spanish-language Hispanics. ${ }^{23}$ The Hispanics are lower in term of education and incomes thus more likely to be uninsured and poorer. This pattern is also similar across European countries. For example the compliance rate is higher across higher income countries (United Kingdom: 91\%, France: $84 \%$ ) than countries with lower income (Spain: 58\%, Italy: $66 \%) .{ }^{24}$ It was found that education level, income level, residence area and age are the main factors influencing understanding and knowledge of antibiotic use. ${ }^{23,24,25,26,27}$ Thus, the above findings suggest that more antibiotic use educational exposure to the people in rural areas, geriatric patients, and education and financially deprived groups are needed. ${ }^{18}$

One of the main causes of antibiotic resistance is the failure to implement basic infection control practices. ${ }^{28,29}$ For instance, important basic measures like hand hygiene should be endorsed in national health campaigns. ${ }^{30}$ This calls for national education campaigns to improve the student and general public's antibiotic knowledge and understanding. For example, the European Centre of Disease Prevention and Control has organized European Antibiotic Awareness Day annually since 2008 to emphasize the need for both GPs and European citizens to use antibiotics responsibly. As a result, in the last 4 years (2008-2012) there has been a signifi- cant fall in community antibiotic prescriptions of cephalosporins (49\%) and quinolones (35\%). ${ }^{31}$ However, a study on educational campaigns in New Zealand showed that there was only a $12 \%$ reduction in patients receiving antibiotics. ${ }^{32}$ proving that the mentioned initiative may not be an ideal way to disseminate antibiotic knowledge. To target groups with lower educational levels, there is a need for higher impact tools for continual reinforcement and repetition. ${ }^{11}$ Concise, tailored slogans and cues to action using television, newspapers, and the internet have proven effective modalities for public education..$^{11,33,34,35}$ Antibiotic campaigns conducted in Belgium, France and England using higher profile communicative tools such as television, repeated for several years, has led to a significant reduction in community antibiotic consumption. ${ }^{36}$ Relating to SEAR, the Antimicrobial Resistance in Indonesia 'Prevalence and Prevention' (AMRIN) study was set up to scrutinize antibiotic patterns and use in Semarang and Surabaya. AMRIN was a two-phased study in which firstly a survey was done to analyze the current antibiotic usage pattern and then interventions were carried out tailored to the population. ${ }^{37}$ Thus, an intervention more suited to the population is carried out. Perception of patient demand is considered to be an important factor in over-prescribing. Prescribers believe that prescribing antibiotics will satisfy patient's expectations despite disobeying infection prevention and control guidelines. ${ }^{38}$ However, several studies show a wide discrepancy, stating that patient satisfaction is more influenced by a clear explanation of the condition and rationale of their treatment. ${ }^{39,40} \mathrm{~A}$ study in the United States reported that $95 \%$ of respondents were satisfied when their prescriber explained an antibiotic was not needed even though the respondents initially thought they needed antibiotics. ${ }^{39}$ In addition, physicians may use antibiotic prescription to bring a difficult consultation to a conclusion due to a fee for a service. ${ }^{41}$ For example in Korea, physicians' income increases proportionally to the amount of patients they attend to. They may use financial incentives as a reason to reduce a patient's visit, thus spending less time on consultation and counseling. ${ }^{12}$ Therefore, a standard treatment guideline with prescribing policies is needed to serve as a benchmark to encourage rational prescribing. Such clinical guidelines should be used as a basis of all education on prescribing. Unfortunately, many developing countries lack government funding to update and regulate specific guidelines, resulting in further antibiotic resistance. ${ }^{42}$

Contrary to regulations, antibiotics are freely available in most countries in SEAR even without prescription. ${ }^{29}$ The lack of implementation of regulations in developing countries encourages wider sales of antibiotics, so anyone can obtain antibiotics over-the-counter from drug stores. ${ }^{15,16,18,42}$ The practice of buying antibiotics directly from pharmacies is evidently to save the time and higher cost from consulting doctors. ${ }^{15,18,19}$ However, for example in India, many of the pharmacies are staffed by unqualified personnel and with only one qualified pharmacist leading to errors in dispensing. Pharmacists also admitted that selling antibiotics over-thecounter is inevitable, as there is a huge patient demand and they would not like to lose business to their competitors. Many of them viewed their profession as a business because there are incentives for achieving sales targets. ${ }^{43}$ An ethnographic study found that there is a reciprocal relationship between pharmacy owners, medicine wholesalers and pharmaceutical industry when it comes to sales of antibiotics. ${ }^{44}$

Data from WHO reveals that common infections causing microorganism strains are already resistant in SEAR. For example, the WHO has published data stating that Escherichia coli is resistant to third-generation cephalosporins (20-95\%) and fluoroquinolones (32-64\%). ${ }^{6}$ Hence, national policies are needed to achieve and maintain good medicine use. A national policy consists of a framework that targets multiple layers of the healthcare system in both the public and private sector to monitor medicine use and coordinate implementation of interventions. Health 
authorities in these countries should start by scaling up previously successful small-scale interventions carried out in SEAR. Then, more interventions targeting the community, particularly with regard to informal and private sectors and private pharmacies, should be implemented. ${ }^{45}$ This proposal is backed by the Third International Conference on Improving Use of Medicines (2011), which states a suitable national policy framework is essential to promote rational use of medicines. ${ }^{46}$ According to information from 2007, there are no medicine policies in SEAR regarding antibiotic non-availability over-the-counter. ${ }^{45}$ Governments in SEAR should take action in building policies to restrict the availability of antibiotics on sale. Although antibiotic resistance is a global issue, all the countries in SEAR are encouraged to take their own initiative to curb antibiotic resistance. Their focus should be on two groups: the community; and healthcare providers. Firstly, initiatives in the community should be strengthened by using educational campaigns to improve antibiotic knowledge. Subsequently, physicians and pharmacists should be asked to provide further explanation regarding antibiotic usage to create awareness of the importance of proper antibiotic consumption.

\section{LIMITATIONS}

We were only able to retrieve data from 5 out of 11 countries in SEAR: India, Korea, Indonesia, Sri Lanka and Thailand. We were unable to find any data concerning Bangladesh, Bhutan, Maldives, Myanmar, Nepal and Timor-Leste. Results from the obtained studies are mostly self-reported which may introduce some bias in the behaviors of respondents.

\section{CONCLUSION}

In conclusion, knowledge of, attitudes to and perceptions of antibiotic use are found to be inappropriate among the general public in SEAR.

\section{ABBREVIATIONS USED}

Antimicrobial resistance (AMR) ; South and East Asian region (SEAR) ; World Health Organisation (WHO); Bachelor of Pharmacy (BPharm); Doctor of Pharmacy (PharmD)

\section{DECLARATIONS}

\section{Ethics approval and consent to participate}

Not applicable because this is a narrative review

\section{Consent for publication}

No specific consent for publication is required because this project is not funded.

\section{Availability of data and material}

Data sharing not applicable to this article as no datasets were generated or analysed during the current study.

\section{Competing interests}

The authors declare that they have no competing interests.

\section{Funding}

This work was supported by KPJ Healthcare University College and Academic and Research Assimilation grants [600-IRMI/DANA 5/3/ARAS (0002/2016)], Ministry of Higher Education and Universiti Teknologi MARA (UiTM). The funders had no role in study design, data collection and analysis, decision to publish, or preparation of the manuscript.

\section{AUTHORS' CONTRIBUTIONS}

JMO, LCM and TMK conceived the concept and study question. FSB, RPP, GBH, JMO and LLH extracted the data and led the search; JMO, LCM and TMK devised the methods and analyzed the data; GBH, JMO and LLH wrote the initial draft; and JMO, FSB, RPP, LCM and TMK revised and finalized the draft for submission.

\section{REFERENCES}

1. World Health Organisation. Antibiotic resistance: Multi-country public awareness survey. Cited 2016]. Available from: http://apps.who.int/medicinedocs/ documents/s22245en/s22245en.pdf. 2015.

2. World Health Organization. Antimicrobial resistance. Cited 2016. Available from: http://www.who.int/mediacentre/factsheets/fs194/en/. 2015.

3. Vanden Eng J, Marcus R, Hadler JL, et al. Consumer Attitudes and Use of Antibiotics. Emerging Infectious Diseases. 2003;9(9):1128-35.

4. Okeke IN, Laxminarayan R, Bhutta ZA, et al. Antimicrobial resistance in developing countries. Part I: recent trends and current status. Lancet Infect Dis. 2005;5(8):481-93.

5. Okeke IN, Lamikanra A, Edelman R. Socioeconomic and behavioral factors leading to acquired bacterial resistance to antibiotics in developing countries. Emerg Infect Dis. 1999;5(1):18-27.

6. World Health Organization. Antimicrobial Resistance: Report of a Regional meeting Jaipur, India, 10-13 November. 2014. p. 6-14. 2015.

7. Gualano MR, Gili R, Scaioli G, Bert F, Siliquini R. General population's knowledge and attitudes about antibiotics: a systematic review and meta-analysis. Pharmacoepidemiol Drug Saf. 2015;24(1):2-10

8. Gandra S, Barter DM, Laxminarayan R. Economic burden of antibiotic resistance: how much do we really know? Clin Microbiol Infect. 2014;20(10):973-80.

9. World Health Organization. Regional Office for South-East Asia. Cited 2016. Available from: http://www.who.int/about/regions/searo/en/. 2016.

10. CDC. Antibiotic Resistance Threats in the United States, 2013. Antibiotic/Antimicrobial Resistance. Cited 2016. Available from: http://www.cdc.gov/drugresistance/threat-report-2013/2014.

11. Kim SS, Moon S, Kim EJ. Public knowledge and attitudes regarding antibiotic use in South Korea. J Korean Acad Nurs. 2011;41(6):742-9.

12. Cho HJ, Hong SJ, Park S. Knowledge and beliefs of primary care physicians, pharmacists, and parents on antibiotic use for the pediatric common cold. Soc Sci Med. 2004;58(3):623-9.

13. Ahmad A, Khan MU, Moorthy J, Jamshed SQ, Patel I. Comparison of knowledge and attitudes about antibiotics and resistance, and antibiotics self-practicing between Bachelor of Pharmacy and Doctor of Pharmacy students in Southern India. Pharm Pract (Granada). 2015;13(1):523.

14. Khan AKA, Banu G, K KR. Antibiotic Resistance and Usage-A Survey on the Knowledge, Attitude, Perceptions and Practices among the Medical Students of a Southern Indian Teaching Hospital. J Clin Diagn Res. 2013;7(8):1613-6.

15. Aditya S, Rattan A. Self-medication among dental undergraduate students with antibiotics: Looking beyond the known. Asian J Pharm Clin Res. 2013;6(Suppl 4): $132-5$

16. Agarwal S, Yewale VN, Dharmapalan D. Antibiotics Use and Misuse in Children: A Knowledge, Attitude and Practice Survey of Parents in India. J Clin Diagn Res. 2015;9(11):Sc21-4

17. Widayati A, Suryawati S, de Crespigny C, Hiller JE. Knowledge and beliefs about antibiotics among people in Yogyakarta City Indonesia: a cross sectional population-based survey. Antimicrob Resist Infect Control. 2012;1(1):38.

18. Gunawardhana CB, Sakeena M, Sivayoganthan C. Awareness of rational medication use and antibiotic self-medication practices among undergraduate students in a university in Sri Lanka. Trop J Pharm Res. 2015;14(4):723-9.

19. Saengcharoen W, Lerkiatbundit S, Kaewmang K. Knowledge, attitudes, and behaviors regarding antibiotic use for upper respiratory tract infections: a survey of Thai students. Southeast Asian J Trop Med Public Health. 2012;43(5):1233-44.

20. World Health Organisation. Antimicrobial Resistance Report of a Regional meeting Jaipur, India, 10-13 November 2014. Cited 16 March 2016. Available from: http://www.searo.who.int/entity/antimicrobial_resistance/sea_hlm_423. pdf?ua=1. 2014

21. You JH, Yau B, Choi KC, Chau CT, Huang QR, Lee SS. Public knowledge, attitudes and behavior on antibiotic use: a telephone survey in Hong Kong Infection. 2008;36(2):153-7.

22. Parimi N, Pinto Pereira LM, Prabhakar P. Caregivers' practices, knowledge and beliefs of antibiotics in paediatric upper respiratory tract infections in Trinidad and Tobago: a cross-sectional study. BMC Fam Pract. 2004;5(1):28.

23. Corbett KK, Gonzales R, Leeman-Castillo BA, Flores E, Maselli J, Kafadar K. Appropriate antibiotic use: variation in knowledge and awareness by Hispanic ethnicity and language. Prev Med. 2005;40(2):162-9.

24. Pechere JC. Patients' interviews and misuse of antibiotics. Clin Infect Dis. 2001;33Suppl 3:S170-3

25. Rousounidis A, Papaevangelou V, Hadjipanayis A, et al. Descriptive study on parents' knowledge, attitudes and practices on antibiotic use and misuse in children with upper respiratory tract infections in Cyprus. Int J Environ Res Public Health. 2011;8(8):3246-62

26. Coco AS, Horst MA, Gambler AS. Trends in broad-spectrum antibiotic prescribing for children with acute otitis media in the United States, 1998-2004. BMC Pediatr. 
2009;9(1):41.

27. Butler CC, Rollnick S, Pill R, Maggs-Rapport F, Stott N. Understanding the culture of prescribing: qualitative study of general practitioners' and patients perceptions of antibiotics for sore throats. Bmj. 1998;317(7159):637-42.

28. Steinberg I. Clinical choices of antibiotics: judging judicious use. Am J Manag Care. 2000; 6(23 Suppl):S1178-88.

29. Nathwani D, Davey P. Antibiotic prescribing-are there lessons for physicians? QJM. 1999;92(5):287-92.

30. Wester CW, Durairaj L, Evans AT, Schwartz DN, Husain S, Martinez E. Antibiotic resistance: a survey of physician perceptions. Arch Intern Med. 2002;162(19):2210-6.

31. McNulty CA. European Antibiotic Awareness Day 2012: general practitioners encouraged to TARGET antibiotics through guidance, education and tools. $J$ Antimicrob Chemother. 2012;67(11):2543-6.

32. Curry M, Sung L, Arroll B, Goodyear-Smith F, Kerse N, Norris P. Public views and use of antibiotics for the common cold before and after an education campaign in New Zealand. NZ Med J. 2006;119(1233):U1957.

33. Marx JJ, Nedelmann M, Haertle B, Dieterich M, Eicke BM. An educational multimedia campaign has differential effects on public stroke knowledge and care-seeking behavior. J Neurol. 2008;255(3):378-84.

34. Bauraind I, Lopez-Lozano JM, Beyaert A, et al. Association between antibiotic sales and public campaigns for their appropriate use. Jama. 2004;292(20):2468-70.

35. Lambert MF, Masters GA, Brent SL. Can mass media campaigns change antimicrobial prescribing? A regional evaluation study. J Antimicrob Chemother. 2007;59(3):537-43.

36. Goossens $H$, Guillemot $D$, Ferech $M$, et al. National campaigns to improve antibiotic use. Eur J Clin Pharmacol. 2006;62(5):373-9.
37. Hadi U, Duerink DO, Lestari ES, et al. Survey of antibiotic use of individuals visiting public healthcare facilities in Indonesia. Int J Infect Dis. 2008;12(6):622-9.

38. Hamm RM, Hicks RJ, Bemben DA. Antibiotics and respiratory infections: are patients more satisfied when expectations are met? J Fam Pract. 1996;43(1): 56-62.

39. Filipetto FA, Modi DS, Weiss LB, Ciervo CA. Patient knowledge and perception of upper respiratory infections, antibiotic indications and resistance. Patient Prefer Adherence. 2008;2: 35-9

40. Ong S, Nakase J, Moran GJ, Karras DJ, Kuehnert MJ, Talan DA. Antibiotic use for emergency department patients with upper respiratory infections: prescribing practices, patient expectations, and patient satisfaction. Ann Emerg Med. 2007;50(3):213-20.

41. Britten N. Patients' demands for prescriptions in primary care. Bmi. 1995;310(6987):1084-5.

42. World Health Organization. The role of education in the Rational Use of Medicines. SEARO Technical Publication Series No 45. New Delhi: WHO-SEARO: World Health Organization, Regional Office for South-East Asia; 2007.

43. Chandy SJ, Mathai E, Thomas K, Faruqui AR, Holloway K, Lundborg CS Antibiotic use and resistance: perceptions and ethical challenges among doctors, pharmacists and the public in Vellore, South India. Indian J Med Ethics. 2013;10(1):20-7.

44. Kamat VR, Nichter M. Pharmacies, self-medication and pharmaceutical marketing in Bombay, India. Soc Sci Med. 1998:47(6):779-94.

45. Holloway KA. Promoting the rational use of antibiotics. Reg Health Forum; 2011;15:122-30.

46. World Health Organisation. Third International Conference for Improving Use of Medicines Cited. 2016;p80. http://appswhoint/medicinedocs/documents/ s21782en/s21782enpdf 2011.

Article History: Submission Date : 03-09-2017 ; Revised Date : 21-09-2017; Acceptance Date : 04-11-2017.

Cite this article: Oh JM, Ming LC, Bakrin FS, Goh BH, Lee LH, Patel RP, Khan TM. Social Aspects of Antibiotic use in the South and East Asian Students and General Population: A Narrative Review. J Young Pharm. 2018;10(1):66-73. 